\title{
Effects of Xuanbai Chengqi decoction on lung compliance for patients with exogenous pulmonary acute respiratory distress syndrome
}

This article was published in the following Dove Press journal:

Drug Design, Development and Therapy

19 February 2016

Number of times this article has been viewed

\author{
Zhengrong Mao' \\ Haifeng Wang ${ }^{2,3}$ \\ 'Department of Critical Care \\ Medicine, The First Affiliated Hospital \\ of Henan, University of Traditional \\ Chinese Medicine, ${ }^{2}$ Department \\ of Respiratory Medicine, The \\ First Affiliated Hospital of Henan \\ University of Traditional Chinese \\ Medicine, ${ }^{3}$ Collaborative Innovation \\ Center for Respiratory Disease \\ Diagnosis and Treatment \& Chinese \\ Medicine Development of Henan \\ Province, Zhengzhou City, Henan, \\ People's Republic of China
}

Objective: To observe the effects of Xuanbai Chengqi decoction on lung compliance for patients with exogenous pulmonary acute respiratory distress syndrome.

Subjects and methods: A total of 53 patients with exogenous pulmonary acute respiratory distress syndrome, who were admitted to the intensive care unit of the First Affiliated Hospital of Henan University of Traditional Chinese Medicine from March 2009 to February 2013, were selected. They were randomly divided into the treatment group ( 25 cases) and the control group (28 cases). Both the groups were treated with conventional treatment and lung-protective ventilation strategy; apart from these, enema therapy with Xuanbai Chengqi decoction was given to the treatment group. Meanwhile, static lung compliance, dynamic lung compliance, peak airway pressure, plateau pressure, and positive end-expiratory pressure (PEEP) for patients in both the groups were observed and recorded at 24, 48, and 72 hours after the drug was used. Moreover, variations in the duration of parenteral nutrition, incidence rate of complications, and case fatality rate in patients after treatment were recorded.

Results: For patients in the treatment group, at 48 and 72 hours after treatment, the static lung compliance and dynamic lung compliance were significantly higher than those in the control group, while plateau pressure, peak airway pressure, and PEEP were significantly lower than those before treatment. At the same time, PEEP for patients in the treatment group at 72 hours after treatment was remarkably lower than that in the control group, showing significant difference $(P<0.05)$. The duration of parenteral nutrition in the treatment group was significantly shorter than that in the control group $(P<0.05)$. Both the incidence rate and the fatality rate of complications, such as abdominal distension and ventilator-associated pneumonia, for patients in the treatment group were distinctly smaller than those in the control group $(P<0.05)$.

Conclusion: Xuanbai Chengqi decoction not only can improve the static lung compliance and dynamic compliance of patients with exogenous pulmonary distress syndrome but also can shorten the parenteral nutrition duration, as well as reducing the complication incidence rate and fatality rate.

Keywords: exogenous pulmonary acute respiratory distress syndrome, static lung compliance, dynamic lung compliance, parenteral nutrition duration, enema

\section{Introduction}

Acute respiratory distress syndrome (ARDS) is a syndrome that is mainly expressed as acute progressive respiratory failure following pulmonary capillary injury induced by intrapulmonary and extrapulmonary causes of disease. According to the causes of a disease, it can be divided into endogenous pulmonary ARDS and exogenous pulmonary ARDS. The pathologic change and respiratory mechanics characterizing patients with the two 
different ARDSs have a relatively great difference. This study achieved better efficacy by selecting patients with extrapulmonary factor-induced ARDS and combining the enema therapy of Xuanbai Chengqi decoction on the basis of conventional treatment and lung-protective ventilation strategy.

\section{Subjects and methods Study subjects}

Fifty-three patients who conformed to the ARDS diagnostic criteria $^{1}$ and were admitted to the intensive care unit of the First Affiliated Hospital of Henan University of Traditional Chinese Medicine from March 2009 to February 2013 were enrolled. The study was approved by the institutional research ethics committee of the First Affilliated Hospital of Henan University of Traditional Chinese Medicine. All patients agreed and signed informed consent before participating in the study. There were 36 males and 17 females, with age ranging from 38 to 76 years and an average age of $59.5 \pm 15.8$ years. Severity of the disease was evaluated according to acute physiology and chronic health evaluation II (APACHE II) criteria. In accordance with the random principle, they were divided into two groups: primary disease in treatment group (25 cases), containing five cases with overall polytrauma, seven cases with acute pancreatitis, two cases with cardiac surgery, five cases with abdominal infection, and six cases following cardiopulmonary resuscitation; and primary disease in control group (28 cases), which included five cases with overall polytrauma, eight cases with acute pancreatitis, one case with cardiac surgery, seven cases with abdominal infection, and six cases following cardiopulmonary resuscitation. The comparisons on ages, sex, APACHE II scores, static lung compliance, dynamic lung compliance, plateau pressure, peak airway pressure, oxygenation index,

Table I Comparisons of blood gas analysis, respiratory mechanics parameters, and pathogenesis of patients enrolled in the two groups (mean \pm standard deviation)

\begin{tabular}{lll}
\hline Items & $\begin{array}{l}\text { Treatment } \\
\text { group } \\
(\mathbf{n}=\mathbf{2 5})\end{array}$ & $\begin{array}{l}\text { Control } \\
\text { group } \\
(\mathbf{n}=\mathbf{2 8})\end{array}$ \\
\hline Age (years) & $60.5 \pm 14.6$ & $58.8 \pm 16.8$ \\
$\mathrm{APACHE} \mathrm{II} \mathrm{score}$ & $18.8 \pm 4.8$ & $19.2 \pm 4.2$ \\
$\mathrm{PaO}_{2} / \mathrm{FiO}_{2}$ & $148 \pm 47$ & $150 \pm 8$ \\
$\mathrm{Vt}(\mathrm{mL} / \mathrm{kg})$ & $6.9 \pm 0.6$ & $6.6 \pm 1.3$ \\
Plateau pressure $\left(\mathrm{cm} \mathrm{H}_{2} \mathrm{O}\right)$ & $27.61 \pm 4.5$ & $26.63 \pm 5.7$ \\
Peak airway pressure $\left(\mathrm{cm} \mathrm{H}_{2} \mathrm{O}\right)$ & $37.62 \pm 6.5$ & $36.53 \pm 7.4$ \\
PEEP $\left(\mathrm{cm} \mathrm{H}_{2} \mathrm{O}\right)$ & $12.6 \pm 3.7$ & $12.5 \pm 3.5$ \\
\hline
\end{tabular}

Abbreviations: APACHE II, acute physiology and chronic health evaluation II; $\mathrm{FiO}_{2}$, fraction of inspired $\mathrm{O}_{2} ; \mathrm{PaO}_{2}$, arterial oxygen pressure; PEEP, positive end-expiratory pressure; $\mathrm{Vt}$, tidal volume. and positive end-expiratory pressure (PEEP) between patients in the two groups showed no significant difference $(P>0.05)$, with comparability (Table 1$)$.

\section{Parameter setting of mechanical ventilation}

Within 24 hours after patients' enrollment, volume-controlled ventilation or pressure-controlled ventilation was adopted according to the different pathogenic conditions. Tidal volume (Vt) was regarded as $6-8 \mathrm{~mL} /$ predicted body weight. Appropriate PEEP level was selected through the oxygenation and clinical profiles, which could reach the minimum PEEP level of targeted oxygenation as far as possible for fraction of inspired $\mathrm{O}_{2}\left(\mathrm{FiO}_{2}\right)<0.6$. Therapeutic goal required that arterial oxygen pressure $\left(\mathrm{PaO}_{2}\right)$ reach $60-80 \mathrm{mmHg}$ or pulse oxygen saturation $\left(\mathrm{SpO}_{2}\right)$ be $90 \%-95 \%$; $\mathrm{pH}$ value be 7.20-7.35, plateau pressure $\leq 30 \mathrm{~cm} \mathrm{H}_{2} \mathrm{O}$, and peak airway pressure $\leq 35 \mathrm{~cm} \mathrm{H}_{2} \mathrm{O}$.

\section{Treatment methods}

With regard to primary disease, conventional treatment (such as prevention of infection, organ function support, shock resuscitation treatment, correction on the disturbance of water and electrolyte balance, and maintenance of acidbase balance) and lung-protective ventilation strategy were conducted for patients in both the groups. Meanwhile, on that basis, the enema therapy using Xuanbai Chengqi decoction was added in the treatment group. For Xuanbai Chengqi decoction, gypsum, rude rhubarb, almond powder, and Pericarpium Trichosanthis were taken as the basic prescription, with the addition or subtraction of components as needed; and $400 \mathrm{~mL}$ of it was selected for strong frying at $36^{\circ} \mathrm{C}-38^{\circ} \mathrm{C}$. The enema was given once every 12 hours over the 3-5 days' course of treatment.

\section{Observation item}

The static lung compliance, dynamic lung compliance, peak airway pressure, plateau pressure, and PEEP for patients in both the groups were observed and recorded at 24, 48, and 72 hours before and after the treatment. Moreover, the duration of parenteral nutrition and incidence rate of complications, such as abdominal distension and ventilator-associated pneumonia, in patients after the treatment were observed, and the fatality rate in 28 days was assessed for the patients.

\section{Statistical methods}

SPSS 17.0 (IBM China Investment Co. Ltd, Beijing, People's Republic of China) statistical analysis software was adopted 
for data processing; the measurement data were represented as mean \pm standard deviation $(x \pm S)$; $\chi^{2}$-test was used for enumeration data; Student's $t$-test was applied for variable differences between the two groups. $P<0.05$ was considered statistically significant.

\section{Results}

\section{Changes in indexes of mechanical ventilation between patients of the two groups before and after treatment}

Static lung compliance and dynamic lung compliance at 48 hours after treatment in the treatment group were significantly higher than those in the control group $(P<0.05)$; plateau pressure at 24,48 , and 72 hours after treatment in the treatment group was remarkably lower than that before treatment $(P<0.05)$; peak airway pressure and PEEP at 48 and 72 hours after treatment were significantly lower than those before treatment $(P<0.05)$; peak airway pressure and PEEO in control group at 24, 48 and 72 hours after treatment had no significant difference compared with those before treatment; plateau pressure at 72 hours after treatment was remarkably lower than that before treatment $(P<0.05)$; PEEP for patients in the treatment group at 72 hours after treatment was significantly lower than that in the control group $(P<0.05)$ (Table 2$)$.

The duration of parenteral nutrition in the treatment group was significantly shorter than that in the control group $(P<0.05)$; both incidence rate and fatality rate of complications, such as abdominal distension and ventilator-associated pneumonia, for patients in the treatment group were distinctly lower than those in the control group $(P<0.05)$.

\section{Comparisons on the rates of complications and case fatality of mechanical ventilation between patients in the two groups}

The duration of parenteral nutrition in the treatment group was significantly shorter than that in the control group $(P<0.05)$; abdominal distension, ventilator-associated pneumonia, and case fatality rate for patients in the treatment group were distinctly lower than those in the control group, showing significant difference $(P<0.05)$ (Tables 3 and 4$)$.

\section{Discussion}

Modern research reports ${ }^{2}$ have shown that endogenous pulmonary ARDS and exogenous pulmonary ARDS have different pathophysiological characteristics, morphological changes, and respiratory mechanical properties. Endogenous pulmonary ARDS, at an early stage, mainly results in alveolar injury, while exogenous pulmonary ARDS is mainly associated with the congestion of pulmonary small vessels and pulmonary interstitial edema, with a relatively normal structure of alveolar space. Moreover, endogenous pulmonary ARDS primarily takes the high elastic resistance of lung as the principal feature, while exogenous pulmonary ARDS

Table 2 Comparisons of relevant indexes of mechanical ventilation for patients in two groups before and after treatment (mean \pm standard deviation)

\begin{tabular}{|c|c|c|c|c|c|c|c|}
\hline Groups & Time & Cases & $\begin{array}{l}\text { Static lung } \\
\text { compliance } \\
\left(\mathrm{mL} / \mathrm{cm} \mathrm{H} \mathrm{H}_{2} \mathrm{O}\right)\end{array}$ & $\begin{array}{l}\text { Dynamic lung } \\
\text { compliance } \\
\left(\mathrm{mL} / \mathrm{cm} \mathrm{H} \mathrm{H}_{2} \mathrm{O}\right)\end{array}$ & $\begin{array}{l}\text { Plateau } \\
\text { pressure } \\
(\mathrm{mmHg})\end{array}$ & $\begin{array}{l}\text { Peak airway } \\
\text { pressure } \\
(\mathrm{mmHg})\end{array}$ & $\begin{array}{l}\text { PEEP } \\
\left(\mathrm{cm} \mathrm{H_{2 }} \text { O) }\right.\end{array}$ \\
\hline \multirow[t]{4}{*}{$\begin{array}{l}\text { Treatment } \\
\text { group }\end{array}$} & $\begin{array}{l}\text { Before } \\
\text { treatment }\end{array}$ & 25 & $23.46 \pm 6.5$ & $22.7 I \pm 5.7$ & $26.6 I \pm 4.5$ & $35.62 \pm 6.5$ & $10.6 \pm 3.7$ \\
\hline & $\begin{array}{l}24 \mathrm{~h} \text { after } \\
\text { treatment }\end{array}$ & 25 & $25.29 \pm 4.7$ & $24.53 \pm 4.5$ & $23.18 \pm 5.4^{* *}$ & $33.58 \pm 5.1$ & $8.7 \pm 3.6$ \\
\hline & $\begin{array}{l}48 \mathrm{~h} \text { after } \\
\text { treatment }\end{array}$ & 25 & $29.66 \pm 6.3^{*}$ & $28.87 \pm 5 . I^{*}$ & $21.89 \pm 4.3^{* *}$ & $30.47 \pm 5.4^{* *}$ & $6.8 \pm 3.1 * *$ \\
\hline & $\begin{array}{l}72 \mathrm{~h} \text { after } \\
\text { treatment }\end{array}$ & 25 & $32.7 I \pm 5.8 *$ & $31.36 \pm 4.2 *$ & $20.69 \pm 4.9 * *$ & $28.78 \pm 5.0 * *$ & $4.5 \pm 2.3^{*}$ \\
\hline \multirow[t]{4}{*}{$\begin{array}{l}\text { Control } \\
\text { group }\end{array}$} & $\begin{array}{l}\text { Before } \\
\text { treatment }\end{array}$ & 28 & $22.87 \pm 7.1$ & $22.82 \pm 4.8$ & $25.83 \pm 5.7$ & $34.53 \pm 7.4$ & $10.5 \pm 3.5$ \\
\hline & $\begin{array}{l}24 \mathrm{~h} \text { after } \\
\text { treatment }\end{array}$ & 28 & $24.18 \pm 5.2$ & $23.68 \pm 5.1$ & $24.64 \pm 4.6$ & $33.82 \pm 4.3$ & $8.9 \pm 3.2$ \\
\hline & $\begin{array}{l}48 \mathrm{~h} \text { after } \\
\text { treatment }\end{array}$ & 28 & $26.29 \pm 5.1$ & $25.14 \pm 5.2$ & $23.49 \pm 4.8$ & $32.7 I \pm 5.0$ & $7.8 \pm 2.7$ \\
\hline & $\begin{array}{l}72 \mathrm{~h} \text { after } \\
\text { treatment }\end{array}$ & 28 & $28.38 \pm 4.8^{* *}$ & $26.4 I \pm 3.6$ & $22.82 \pm 4 . I^{* *}$ & $31.66 \pm 3.6$ & $7.1 \pm 2.1$ \\
\hline
\end{tabular}

Notes: Comparing the same time points in the control group, $* P<0.05$; comparing with the same group before treatment, $* * p<0.05$. Abbreviations: PEEP, positive end-expiratory pressure; h, hours. 
Table 3 Comparisons of the days of abdominal distension and parenteral nutrition for patients in the two groups (mean \pm standard deviation)

\begin{tabular}{lll}
\hline Groups & Cases & $\begin{array}{l}\text { Parenteral } \\
\text { nutrition, days }\end{array}$ \\
\hline Treatment group & 25 & $2.2 \pm 1.2^{*}$ \\
Control group & 28 & $4.3 \pm 2.1$ \\
\hline
\end{tabular}

Note: Comparing with the control group, $* P<0.05$.

involves the simultaneous increase in the elastic resistance of lung and chest wall, which is the reason that patients with ARDS easily develop increase in intra-abdominal pressure and show disease changes, such as intestinal mucosal hyperemia, slowing of peristalsis, and intestinal obstruction, which aggravate the progression of ARDS. Nei Jing has described a "Fei he da chang", which means that the lung and the large intestine are related in both interior and exterior aspects. In the meridians-and-collateral theory of Chinese medicine, the lung and the large intestine are the viscera of the exterior and the interior between yin and yang organs and are closely related to each other. It is clinically indicated that combined treatment of the lung and the large intestine, compared with the simple treatment of single visceral organ, shows significant improvement in treatment efficacy. Xuan Bai Chengai decoction, which is adapted from Identification of Warm Disease written by Wu Ju-tong, who was a famous expert on seasonal febrile diseases in the Qing dynasty, is one of the five efficacious prescriptions for "Xia zhi bu tong" of Yang Ming warm disease. In the prescription, gypsum has the effect of clearing heat from the lung, rude rhubarb in purgating heart and bowels, almond powder in ventilating the lung and arresting cough, and Pericarpium Trichosanthis in moistening the lung for removing phlegm. When these drugs are combined for use, they have an effect in dispersing and lowering lung qi, clearing lung and eliminating phlegm, capturing fu-viscera, and exclusively treating the same disease syndrome of lung and large intestine. ${ }^{3}$ The results in this study found that the enema therapy with Xuanbai Chengqi decoction for patients with exogenous pulmonary ARDS was able to augment its lung compliance,

Table 4 Comparisons of mechanical ventilation complication and fatality for patients in the two groups (cases [\%])

\begin{tabular}{lllll}
\hline Groups & Cases & $\begin{array}{l}\text { Abdominal } \\
\text { distension }\end{array}$ & $\begin{array}{l}\text { Ventilator- } \\
\text { associated } \\
\text { pneumonia }\end{array}$ & $\begin{array}{l}\text { Fatality in } \\
\text { 28 days }\end{array}$ \\
\hline Treatment group & 25 & $3(12)^{*}$ & $8(32)^{*}$ & $5(20)^{*}$ \\
Control group & 28 & $19(67.8)$ & $16(57.1)$ & $12(42.8)$ \\
\hline
\end{tabular}

Note: Comparing with the control group, $* P<0.05$. improve the gastrointestinal function, reduce the disease complication rate, and speed up the recovery from the disease, which were considered to be due to the following reasons.

\section{Increasing gastrointestinal peristalsis and decreasing intra-abdominal pressure}

The research by Pelosi et $\mathrm{al}^{4}$ indicated that the intra-abdominal pressure in patients with exogenous pulmonary ARDS was three times higher than that of patients with endogenous pulmonary ARDS. At the same time, mucosal hyperemia of gastrointestinal tract, hydrops and pneumatosis of gastrointestinal tract, slowing of peristalsis, and thickening of the wall and the inner diameter of the intestinal tract in exogenous pulmonary ARDS were more common than in endogenous pulmonary ARDS. Gastrointestinal dysfunction among patients with ARDS led to the increase of intra-abdominal pressure and the uplift of diaphragm, further decreasing the thoracic cavity and reducing the static lung compliance and dynamic lung compliance. ${ }^{5}$ It is of vital importance for critical patients to maintain normal physiological function of the intestine. ${ }^{6}$ The early enteral nutrition had the ability to improve the blood flow of the viscera, meet the energy need, and reduce the systemic inflammatory responses, thus improving the prognosis. Xuanbai Chengqi decoction had the effect of enhancing gastrointestinal peristalsis, speeding emptying, and improving gastrointestinal function, which could effectively decrease patients' intra-abdominal pressure, improve both static lung compliance and dynamic lung compliance, and simultaneously reduce patients' duration of parenteral nutrition. Studies by Cui et $\mathrm{al}^{7}$ showed that after nasal feeding with Xuanbai Chengqi decoction combined with a modified prescription for 5 days, patients' extraabdominal pressure was significantly decreased compared to that before treatment and that in the control group.

\section{Protecting intestinal mucosa to prevent the translocation of flora}

Multiple pathogenic factors were able to cause intestinal mucosal injury, which helped the multiple flora in the enteric cavity translocate into circulation, thus producing numerous endotoxins and finally resulting in the incidence of ARDS. ${ }^{8}$ Meanwhile, the translocation of flora and endotoxins in blood was able to rapidly destroy the integrity of the intestinal mucosal barrier and promote invasion of more bacteria and endotoxins unceasingly into the body, forming a vicious circle. ${ }^{9}$ Xuanbai Chengqi decoction not only had the ability to clear the heat of lung, stomach, and intestines and cleanse 
the accumulation of toxins but also could improve blood circulation in the intestinal tract, protect the intestinal barrier, and decrease the translocation of flora and free endotoxins present in the enteric cavity among tissues by excluding the intestinal bacteria and the produced endotoxin, thus reducing the incidence of ARDS. Chen et $\mathrm{al}^{10,11}$ had reported that Rheum officinale was able to promote the proliferation of the intestinal mucosal goblet cells and increase mucus secretion in the enteric cavity; meanwhile, it had a better scavenging effect on the oxygen radicals in the intestinal tract, liver, and blood plasma, thus decreasing the translocation of intestinal bacteria, lowering the permeability of intestinal mucosa, and reducing the incidence of ARDS. Moreover, Wang et $\mathrm{al}^{12}$ had found that $R$. officinale in combination with glutamine was able to protect the gastrointestinal mucosa, alleviate the level of inflammatory response, and enhance the citrulline level in plasma, which was beneficial to the recovery of barrier function of the gastrointestinal mucosa. Studies by Meng et $\mathrm{al}^{13}$ showed that on treatment with Xuanqi Chengbai decoction, rats bearing gut-origin sepsis showed improvement in the degree of intestinal mucosa injury and the intestinal barrier function was protected.

\section{Alleviating pulmonary edema and improving respiratory function}

Studies by Muller-Leisse et $\mathrm{al}^{14}$ found that the major pathological changes in exogenous pulmonary ARDS were pulmonary small-vessel congestion and pulmonary interstitial edema but relatively normal structure of alveolar space. Xuanbai Chengqi decoction had the effect of ventilating the lung and depressing qi, as well as smoothing the abdomen and excreting water. At the same time, it also had the ability to speed up gastrointestinal peristalsis, increase the functioning of the gastrointestinal tract, and augment the elimination of toxins and moisture in vivo, thus alleviating pulmonary congestion and pulmonary interstitial edema. In this study, the urine volume and defecation frequency in patients of the treatment group were significantly increased, airway secretion and lung rale were decreased, and respiratory function was remarkably improved, which suggested that Xuanbai Chengqi decoction had a better diuresis effect.

\section{Adjusting inflammatory factors and alleviating inflammatory response}

Modern studies have shown that ARDS is the result of inflammatory response caused by the interaction of various inflammatory factors. The release of various inflammatory factors in vivo, such as tumor necrosis factor- $\alpha$, interleukin-6 interleukin-8, and interferon- $\gamma$, which was caused by numerous endotoxins getting released into the blood, caused extensive inflammatory injury to the body, which was the vital element for ARDS incidence. ${ }^{15}$ Zhang et $\mathrm{al}^{16}$ reported that Qingfei Chengqi decoction was able to alleviate the apoptosis of lung tissues after acute lung injury rats caused by severe intra-abdominal infection or have the effect of reducing the level of inflammatory reactions and enhancing the expression of apoptosis-related protein Bcl-2 in lung tissues after Chinese medicine intervention. In this study, the fatality rate for patients treated with Xuanbai Chengqi decoction was significantly lower than that in the control group, which was related to the fact that this drug had the ability to correct the imbalance in inflammatory factors among patients with ARDS, alleviate the inflammatory response, and improve and prolong a series of pathological change process.

\section{Conclusion}

It is concluded that the enema therapy with Xuanbai Chengqi decoction was able to enhance the static lung compliance and dynamic lung compliance of patients with exogenous pulmonary ARDS, improve patients' gastrointestinal function, and reduce the duration of parenteral nutrition; simultaneously, it could lower the complication incidence rate and disease fatality rate, with distinct efficacy, low cost, and little side effects. A better method for treating exogenous pulmonary ARDS may be by using a combination of Chinese traditional and Western medicines. Due to the few cases enrolled in this study and the clinical grouping, which was not in accordance with the latest Berlin Definition of ARDS, further clinical studies still need to be carried out.

\section{Acknowledgments}

The author thanks the Specific Subjects of Scientific Researches in Traditional Chinese Medicine of Henan Province for their financial support (Foundation item: 2014ZY02029). This study was also sponsored by the Program for Research Project for Practice Development of National TCM Clinical Research Bases (grant number JDZX2012028), the National Natural Science Foundation of China (grant numbers 81573804 and 81102576), the Program for Science \& Technology Innovation Talents in Universities of Henan Province (grant number 14HASTIT029), the Program for Traditional Chinese Medicine Science Foundation of Henan Province (grant number 2014ZY01011), and the Program for Science \& Technology Innovation Talents in Henan College of Chinese Medicine (2012XCXRC02). 


\section{Disclosure}

The author reports no conflicts of interest in this work.

\section{References}

1. Society of Critical Care Medicine; Chinese Medical Association. Guidelines for management of acute injury/acute respiratory distress syndrome: an evidence-based update by the Chinese Society of Critical Care Medicine (2006). Chin Crit Care Med. 2007;16(4):343-349.

2. Xie LX, Liu YN. Endogenous pulmonary acute respiratory distress syndrome and exogenous pulmonary acute respiratory distress syndrome. Chin J Intern Med. 2003;42(7):517-519.

3. Qing WT. Identification of Warm Disease [M]. Beijing: People's Medical Publishing House; 2005:5.

4. Pelosi P, Colombo G, Gamberoni C, et al. Effects of positive endexpiratory pressure on respiratory function in head-injured patients. Intensive Care Med. 2000;26:A450.

5. Pelosi P, Vargas M. Mechanical ventilation and intra-abdominal hypertension: 'beyond good and evil'. Crit Care. 2012;16:187.

6. Chen XH, Xiao QM. Intestinal protection treatment progress of multiple organ dysfunction syndrome. Chin J Integr Tradit West Med Intensive Crit Care. 2014;21(2):155-158.

7. Cui K, Lin RH, Chen ZT, et al. Clinical observation of Xuanbai Chengqi decoction in treating acute respiratory distress syndrome. J Emerg Tradit Chin Med. 2013;22(2):294-295.

8. Badami CD, Senthil M, Caputo FJ, et al. Mesenteric lymph duct ligation improves survival in a lethal shock model. Shock. 2008;30:680-685.
9. Zhang Y-M, Zhang S-K, Cui NQ. Intravenous infusion of mesenteric lymph from severe intraperitoneal infection rats cause lung injury in healthy rats. World Gastroenterol. 2014;20(16):4771-4777.

10. Chen DC, Jing BW. Protective effect of rhubarb on gut barrier. Chin Crit Care Med. 1996;8(8):449-451.

11. Chen DC, Ma LQ, Liu SZ. Effects of rhubarb on intestinal flora and bacteria translocation in rats with sepsis. Chin Crit Care Med. 2009; 21(1):17-20.

12. Wang XF, Shen YL, Zheng F, Ye H-W, Chen D-C. A research on effects of rhubarb combined with glutamine on repair of gut mucosal barrier injury in rats. Chin J Integr Tradit West Med Intensive Crit Care. 2013;20(6):341-344.

13. Meng FS, Guo YJ, Hou J, et al. Experimental study of Xuanbai Chengqi decoction on the intestinal barrier function protection of rats with sepsis. J Math Med. 2011;24(2):151-152.

14. Muller-Leisse C, Klosterhalfen B, Hauptmann S. Computed tomography and histologic results in the early stages of endotoxin-injured pig lungs as a model for adult respiratory distress syndrome. Invest Radiol. 1993; 28(1):39-45.

15. Buttenschoen K, Kornmann M, Berger D, Leder G, Beger HG, Vasilescu C. Endotoxemia and endotoxin tolerance in patients with ARDS. Langenbecks Arch Surg. 2008;393(4):473-478.

16. Zhang YM, Cui NQ, Zhang SK. The effect of Qingfei Chengqi decoction on lung tissue cell apoptosis in rats with severe intraperitoneal infection. Chin J Integr Tradit West Med Intensive Crit Care. 2014;21(3): 165-169.
Drug Design, Development and Therapy

\section{Publish your work in this journal}

Drug Design, Development and Therapy is an international, peerreviewed open-access journal that spans the spectrum of drug design and development through to clinical applications. Clinical outcomes, patient safety, and programs for the development and effective, safe, and sustained use of medicines are a feature of the journal, which

\section{Dovepress}

has also been accepted for indexing on PubMed Central. The manuscript management system is completely online and includes a very quick and fair peer-review system, which is all easy to use. Visit http://www.dovepress.com/testimonials.php to read real quotes from published authors.

Submit your manuscript here: http://www.dovepress.com/drug-design-development-and-therapy-journal 